\title{
Daily activity rhythms in temperate coastal fishes: insights from cabled observatory video monitoring
}

\author{
J. Aguzzi1 ${ }^{1, *}$, V. Sbragagliaa ${ }^{1}$, G. Santamaría ${ }^{2}$, J. Del Río ${ }^{2}$, F. Sardà ${ }^{1}$, M. Nogueras ${ }^{2}$, \\ A. Manuel $^{2}$
}

${ }^{1}$ Marine Science Institute (ICM, CSIC), Paseo Marítimo de la Barceloneta, 37-49, 08003 Barcelona, Spain

${ }^{2}$ SARTI Research Group, Electronics Department (Universitat Politècnica de Catalunya; UPC), Rambla de la Exposición 24, 08800 Vilanova i la Geltrú-Barcelona, Spain

\begin{abstract}
The rhythmic behavior of marine species generates uncertainties in population and biodiversity assessments if the frequency of sampling is too low and irregular over time. Few attempts have been made to link community changes to the rhythmic behavior of individuals within populations. Cabled video observatories can be used to explore community changes over different temporal windows as a result of the activity rhythms of individuals within populations. In this study, we used, for the first time, a coastal cabled observatory (OBSEA) to video monitor activity rhythms of different fish species within an artificial reef area at a high frequency. During 1 mo, 30 min daily count patterns were continuously measured and compared with the corresponding solar irradiance. A significant $(p<0.05)$ day-night patterning was observed in the majority of recognized taxa by Chi-Square periodogram analysis. Three types of rhythms were identified in waveform plotting: (1) diurnal (Chromis chromis, Coris julis, Diplodus annularis, D. cervinus, D. sargus, D. vulgaris, Serranus cabrilla, Dentex dentex, Symphodus sp.); (2) nocturnal (Atherina sp. and Scorpaena sp.); and (3) crepuscular (Apogon imberbis, Oblada melanura, and Spicara maena). Diurnal species clustered around maximum averaged irradiance (computed from a cosinor analysis). The results were discussed evaluating whether visual count time series represent a reliable proxy for the swimming activity rhythms of individuals and whether the complex habitat use of coastal fishes would require the use of spatial networks of cameras.
\end{abstract}

KEY WORDS: OBSEA · Cabled video observatories · Swimming rhythms · Western Mediterranean $\cdot$ Coastal areas $\cdot$ Temperate fishes $\cdot$ Irradiance $\cdot$ Daily activity

\section{INTRODUCTION}

Light cycles drive the activity patterns of animals via the process of natural selection because the level of environmental illumination influences the typology and the strength of all inter- and intra-specific interactions (e.g. feeding, predator evasion; Pulcini et al. 2008). Accordingly, the majority of species studied to date show a marked diurnal, nocturnal, or crepuscular patterning of their ecological niche (reviewed by Kronfeld-Schor \& Dayan 2003, Aguzzi \& Com- pany 2010). Marine species are not an exception to this rule. The rhythmic behavior of animals results in massive displacements. These events influence our population and biodiversity assessments if the frequency of sampling is too low and irregular through time (Aguzzi \& Company 2010, Aguzzi et al. 2012).

These general principles may be applicable to highly motile organisms such as fishes, whose activity rhythms have a deep and still poorly understood influence on our perception of changes in community composition over periods of days and over the 
seasons in coastal areas (Condal et al. 2012). The consideration of these aspects of activity and perceived community structure is critical in monitoring the effectiveness of marine protected areas, in improving survey designs for fisheries assessment, and in evaluating habitat use (Willis et al. 2000). To date, few attempts have been made to link temporal changes in communities to the behavioral rhythms of individuals within populations (Aguzzi et al. 2011a). Fish swimming/resting activity rhythms have traditionally been studied through laboratory experiments (reviewed by Reebs 2002, LópezOlmeda \& Sánchez-Vázquez 2010, 2012). Over the past few decades, however, the activity rhythms of a variety of species have also been the focus of increased study in the field based on a variety of sampling techniques subject to technical constraints on the repetition and duration of sampling. These techniques include the use of beach seines (Harmelin-Vivien \& Francour 1992, Letourneur et al. 2001, Dulčić et al. 2004, 2005, Tutman et al. 2007, 2010), trawl surveys (Petrakis et al. 2001), and visual census surveys (Spyker \& Van den Berghe 1995, Willis et al. 2006, Azzurro et al. 2007, 2013, Fischer et al. 2007).

The efficient monitoring of fish behavioral rhythms in the field would require hourly sampling over several consecutive $24 \mathrm{~h}$ cycles (Bahamon et al. 2009, Aguzzi \& Company 2010). The recent implementation of cabled video observatories may provide a new technological solution for studying the activity rhythms of fishes in the field at the required high frequency and duration (from minutes to months) (Glover et al. 2010, Aguzzi et al. 2010, 2012, Matabos et al. 2011). The monitoring capability of these platforms has recently been evaluated for fishes in coastal areas, but only relative to the detection of seasonal abundance variations (Barans et al. 2005, Condal et al. 2012). These platforms have never been used to measure $24 \mathrm{~h}$ swimming rhythms. The feasibility of measuring these rhythms should be evaluated relative to the constraints imposed by the use of a single still camera as an observation point (Barans et al. 2005).

In the present study, we used the new Western Mediterranean OBSEA coastal cabled video observatory to measure the activity rhythms of fishes at a high frequency (min) continuously over 1 mo. Our aim was to assess the relationship of these rhythms to the day-night cycle. We also critically evaluated whether the obtained count patterns can be used as a reliable proxy for swimming rhythms of local fish populations considering the complex patterns of habitat use. We also gathered solar irradiance data in conjunction with video monitoring because this environmental characteristic is one of the major evolutionary forces shaping fish behavior (Horodysky et al. 2008, 2010).

\section{MATERIALS AND METHODS}

The Western Mediterranean Expandable SEAfloor OBservatory (OBSEA; www.OBSEA.es) is a cabled video platform located at a depth of $20 \mathrm{~m}$ within the Colls i Miralpeix Marine Reserve, $4 \mathrm{~km}$ off Vilanova i la Geltrú (Catalonia, Spain) (Fig. 1A) (Aguzzi et al. 2011b). The observatory is equipped with an OPT-06 Underwater IP Camera (OpticCam, Ocean Presence Technologies), which can acquire digital images of the environment surrounding the OBSEA at $360^{\circ}$ with a resolution of $640 \times 480$ pixels $(\mathrm{Mpeg} / \mathrm{Mjpeg}$; $18 \times$ optical zoom).

OBSEA was recently equipped with a nocturnal lighting system consisting of 2 white light LED arrays. The system was automatically enabled $2 \mathrm{~s}$ prior to image acquisition to allow the lights to warm up and attain the maximum amount of homogeneous illumination, and was switched off immediately after. Lamps illuminated the artificial reef panel (see below) from a distance of $1 \mathrm{~m}$ behind the camera. Each array consisted of 13 high-luminosity white LEDs with a total power of $30 \mathrm{~W}$ and generated an emission power of $3800 \mathrm{~lm}\left(63 \mathrm{~W} \mathrm{~m}^{-2}\right)$ along the maximum light propagation vector at an angle of $38^{\circ}$. The lights were switched on and off by a LabView application that also controlled the camera white balance.

\section{Image acquisition, fish counting, and light sampling}

In previous cabled observatory video studies in deep-sea areas, fluctuations in video-counted individuals have been used as a proxy of population activity rhythms (reviewed by Aguzzi et al. 2011a). Accordingly, we custom-designed the image acquisition for the present study to achieve fully automated and temporally scheduled operation. We acquired images over 30 min periods during 1 mo (22 October to 22 November 2011, starting and ending at 00:00 h and 15:00 h local time, respectively); a storm on 22 November prevented a longer observation period because it displaced the panel representing the camera's Region of Interest (RoI, see below). A procedure controlling the ON-OFF status of the lighting immedi- 


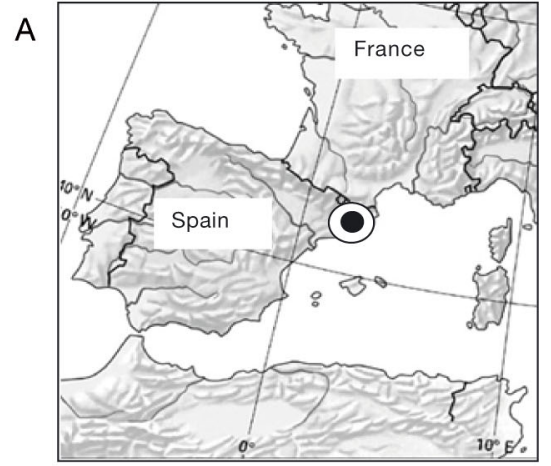

C

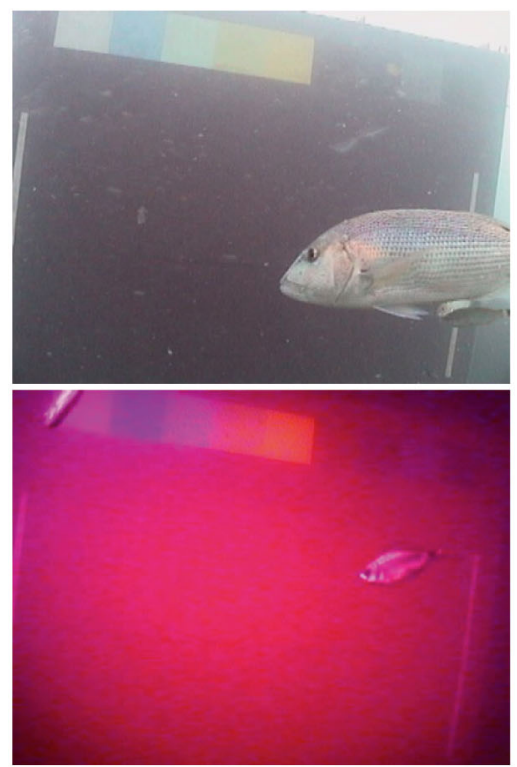

B
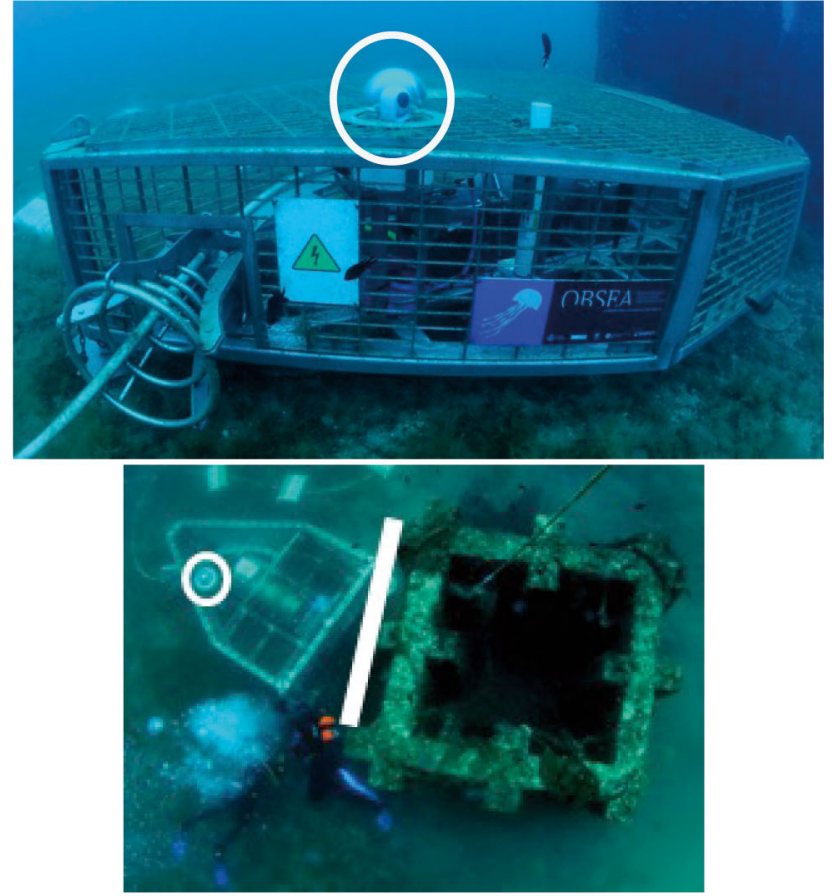

Fig. 1. (A) The OBSEA location in the Western Mediterranean coastal area; (B) a detailed lateral view of the platform, showing the position of the Cyclops camera (white circle), and a superior view showing the position of the platform relative to the artificial reef (quadrat) and the panel (thick white line). (C) Two photographs of the camera Region of Interest (RoI), centred on the panel surface, are shown to represent the images used for fish counting (Dentex dentex in the upper photograph; Oblada melanura in the lower photograph, with an unrecognisable individual in the upper left corner). These images were obtained during the daytime $(13: 30 \mathrm{~h})$ and at night $(01: 30 \mathrm{~h})$, respectively, from 2 to 3 November 2011 ately before and after image acquisition was implemented to avoid constant lighting throughout the monitoring period because such lighting may disrupt behavioral observations (Aguzzi et al. 2010, Matabos et al. 2011). A constant lights-on status in this coastal area at night was avoided to decrease light avoidance or attraction to the minimum possible amount (Longcore \& Rich 2004).

An artificial reef was placed at a distance of approximately $3 \mathrm{~m}$ from the camera. A red methacrylate panel of $220 \times 220 \mathrm{~cm}$ was installed next to the artificial reef (Fig. 1B) at approximately $2 \mathrm{~m}$ above the seabed to provide a standard Region of Interest (RoI) for fish counting. The camera was always aimed at a $45^{\circ}$ angle towards the panel, which was elevated above the horizontal field of view.

To relate the detected activity rhythms of the fishes to changes in environmental illumination, we gathered data on atmospheric irradiance $\left(\mathrm{W} \mathrm{m}^{-2}\right)$ at times corresponding to image acquisition. We used data automatically recorded by a Catalan Meteorological
Service station in Sant Pere de Ribes $(6 \mathrm{~km}$ from OBSEA), which measures global radiation as the sum of the direct and diffuse components of solar irradiance using a silicon photodiode with wide spectral response from 400 to $780 \mathrm{~nm}$. Atmospheric irradiance was used since wavelengths of 400 to $500 \mathrm{~nm}$ (blues and greens) are less attenuated in seawater than longer wavelengths >550 nm (yellows and reds) (Maritorena \& Guillocheau 1996). In fact, blue light is the major regulator of marine species behavior given its elevated penetrability into the water column (Aguzzi \& Company 2010).

Taxa classification (performed with FISHBase; Froese \& Pauly 2009) and counting were conducted for each picture following Condal et al. (2012). We reported the total number of visible fishes (termed the species assemblage), the number of non-classifiable individuals (i.e. those classified as unknown), and the number of individuals for each recognizable taxonomic group (resolved to the lowest possible level). 


\section{Time series analysis}

Time series analysis was performed separately for each time series of visual counts (i.e. the species assemblage, the unknown individuals, and the counts for individual taxonomic groups) with the local time as the reference. In order to obtain a global overview of fish activity over consecutive light intensity cycles of variable strength, we first plotted visual count and irradiance data versus the local time (see Fig. 2).

A Chi-Square periodogram analysis (Sokolove \& Bushell 1978) was used to screen the occurrence of significant $(\mathrm{p}<0.05)$ periodicities within intervals of 480 and 1500 min (equal to 8 and 25 h, respectively). We used this range of frequencies to detect unimodal or bimodal patterns in the time series. The periodogram analysis was performed with El Temps software (www.el-temps.com; Prof. A. Diez-Noguera, University of Barcelona). We reported the percentage of variance represented by each significant periodicity detected. This measure is proportional to the rhythm strength (Cambras et al. 2000, Refinetti et al. 2007, Chiesa et al. 2010).

A waveform analysis was conducted to assess the phase of the visual count rhythms in terms of the peak timing. The time series were subdivided into $24 \mathrm{~h}$ segments. A consensus fluctuation over a standard period of $24 \mathrm{~h}$ was then obtained by averaging all values of the different segments at the corresponding timing value. The resulting mean $( \pm \mathrm{SD})$ values were plotted to determine the waveform. The phase was then computed according to the Midline Estimating Statistic of Rhythm (MESOR) method (Aguzzi et al. 2006). The MESOR value was estimated by reaveraging all waveform values and the result presented as a threshold line on the waveform plot. All mean values above the line defined a significant increment in activity (i.e. in the visual counts). The onset and offset of activity were estimated by considering the first and the last value above MESOR, respectively. Because the rhythms analyzed in this study showed substantial variability, the activity was considered continuous if no more than 3 values occurred below the MESOR. The waveform analysis was repeated for the irradiance data plotted with each waveform to estimate the light levels at which the studied species showed significant increases in the rate of behavioral activity.

A Rayleigh Z-test was applied to the time series of the different taxa recognized (excluding taxa for which only one visual count was obtained) and of the irradiance data to assess the temporal relationship between the 2 series. The acrophase of the rhythms was first determined for all taxa with a cosinor test $(\mathrm{p}=0.05)$ (Nelson et al. 1979). The different acrophases obtained were then plotted using a Rayleigh Z-test (Batschelet 1981) to study their temporal clustering (i.e. phase distribution) in circular coordinates $(24 \mathrm{~h})$ representing the time of day. The monthly averaged photophase was represented on this plot by considering the irradiance waveform onset and offset (from MESOR) as markers of sunrise and sunset, respectively.

\section{RESULTS}

We collected 1520 images (Table 1) representing 19 different taxa. Of these taxa, 16 were classified at the species level. We classified the remaining 3 taxa (Atherina sp., Scorpaena sp., Symphodus sp.) at the genus level because the images acquired did not furnish sufficient morphological detail to allow species identification.

\section{The observed species assemblage}

The taxa detected showed markedly different video counts (Table 1). Chromis chromis and Diplodus vulgaris were the most abundant taxa ( $\mathrm{N}=2525$ and $\mathrm{N}=1152$, respectively). In fact, fishes of the genus Diplodus together represented $21.6 \%$ of all visual counts $(\mathrm{N}=1527)$. Conger conger, Diplodus puntazzo, Epinephelus marginatus, Symphodus tinca, and Sciaena umbra appeared only once and were, therefore, excluded from all subsequent time series analyses. The visual counts of Scorpaena sp. most likely represented a very small number of individuals residing in proximity to the OBSEA platform.

\section{Activity rhythms}

The visual count time series for the selected species (i.e. the relatively abundant species; Table 1) showed rhythmic fluctuations of varying strength (Fig. 2) depending on the total count levels. The temporal patterning varied in strength over consecutive days, but rhythmicity was immediately visible in the majority of groups. All data sets showed a linkage with environmental illumination (i.e. irradiance), which also varied markedly over consecutive days. For example, the maximum and minimum daytime irradiance values were $644 \mathrm{~W} \mathrm{~m}^{-2}$ (26 October) and $76 \mathrm{~W}$ $\mathrm{m}^{-2}$ (28 October), respectively. 


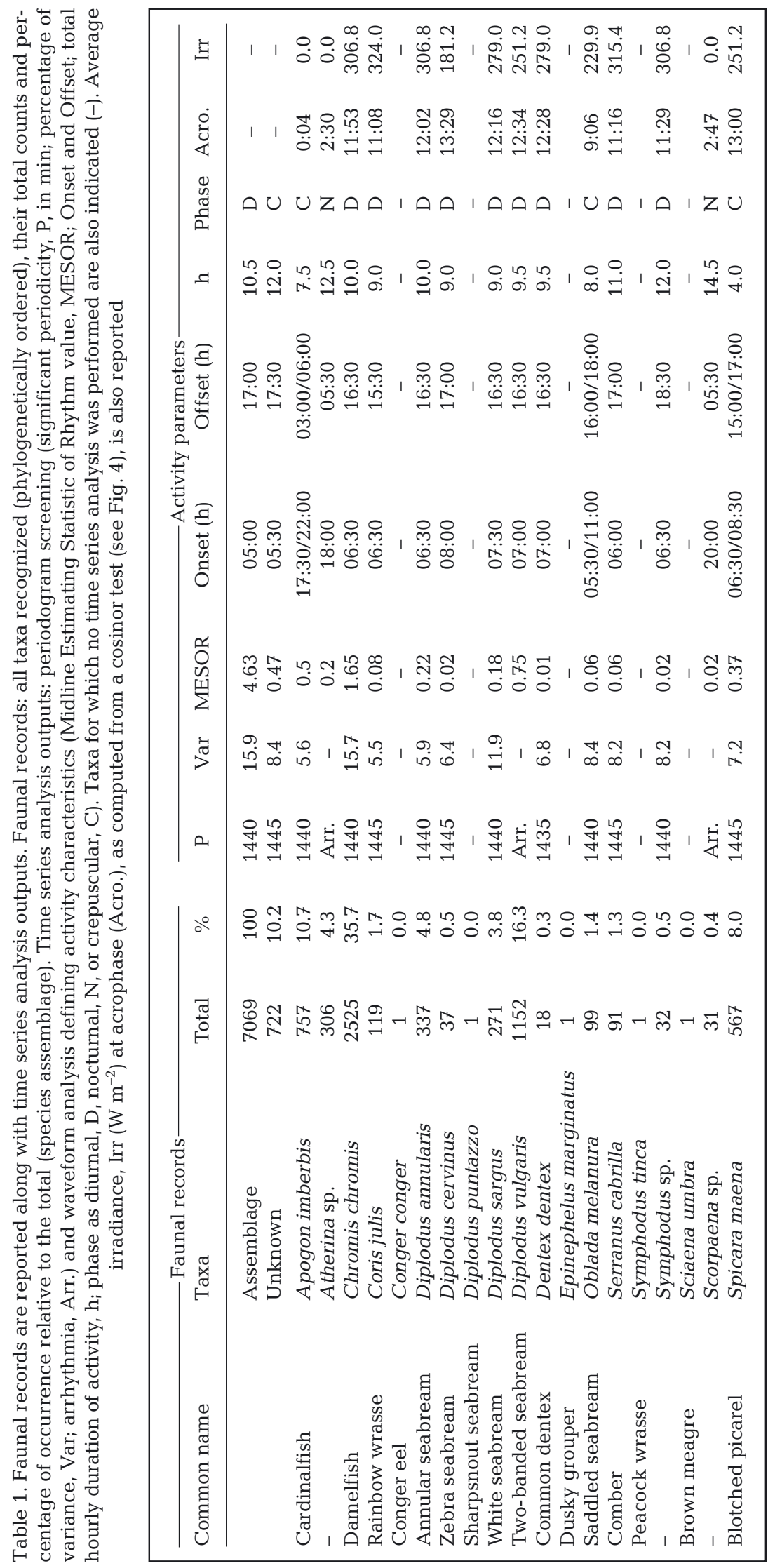

The periodogram analysis revealed significant daily periodicities (i.e. 1440 $\pm 5 \mathrm{~min}$, mean $\pm \mathrm{SD}$ ) in the majority of time series for the different taxa (Table 1). With few exceptions, the detected rhythms represented more than $10 \%$ of the total variance. Stronger rhythms were reported for the whole species assemblage, which was dominated by the visual counts of Chromis chromis (also showing levels higher than $10 \%$ of the total variance). No discernible rhythmicity was detected for Atherina sp., Diplodus vulgaris, or Scorpaena sp. In particular, Atherina sp. showed arrhythmia based on the very low counts reported during the entire testing period, with the exception of a large schooling event observed from $04: 30$ to $05: 30 \mathrm{~h}$ on 5 November (Fig. 2d). Arrhythmia was similarly reported in Scorpaena sp. based on the extremely scattered and low abundance counts (Fig. 2q). Arrhythmia was reported for $D$. vulgaris based on the highly variable visual counts. This variability was dampened during the second half of the month of observations, with the only schooling peak observed from 11:00 to $13: 30 \mathrm{~h}$ on 11 November (Fig. 21).

A waveform analysis was conducted to assess the activity phase of the visual count rhythms (i.e. the peak timing) for each targeted taxon over the $24 \mathrm{~h}$ cycle (Table 1). The waveform output plot for the species assemblage showed the presence of a general and marked diurnal phase (Fig. 3a) that started and ended a few hours before and after sunrise and sunset, respectively (i.e. values above the MESOR

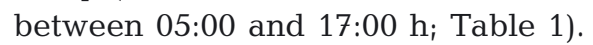
At night, the visual counts for all fishes dropped approximately 7 -fold relative to the values observed close to midday. This finding suggested a diurnal phase of $12 \mathrm{~h}$ for the majority of the observed species. Fishes within the unknown category showed a crepuscular pattern, although greater numbers were reported during the day than at night (Fig. 3b). 
The diurnal character of the visual counts for the local fish assemblage was due primarily to a group of taxa whose detections increased significantly during the day (Fig. 3e-i,l,o,p, respectively): Chromis chromis, Coris julis, Diplodus annularis, Diplodus cervinus, Diplodus sargus, Diplodus vulgaris, Serranus cabrilla, and Symphodus sp. We also included Dentex dentex in this category because sparse increases occurred throughout the day, whereas no observations of this species were reported after sunset (Fig. 3m). Although these 9 taxa showed markedly different count levels, all of them presented a significant $24 \mathrm{~h}$ periodicity in the periodogram analysis with the exception of $D$. vulgaris, whose counts in the second half of the month were extremely scattered (Table 1).
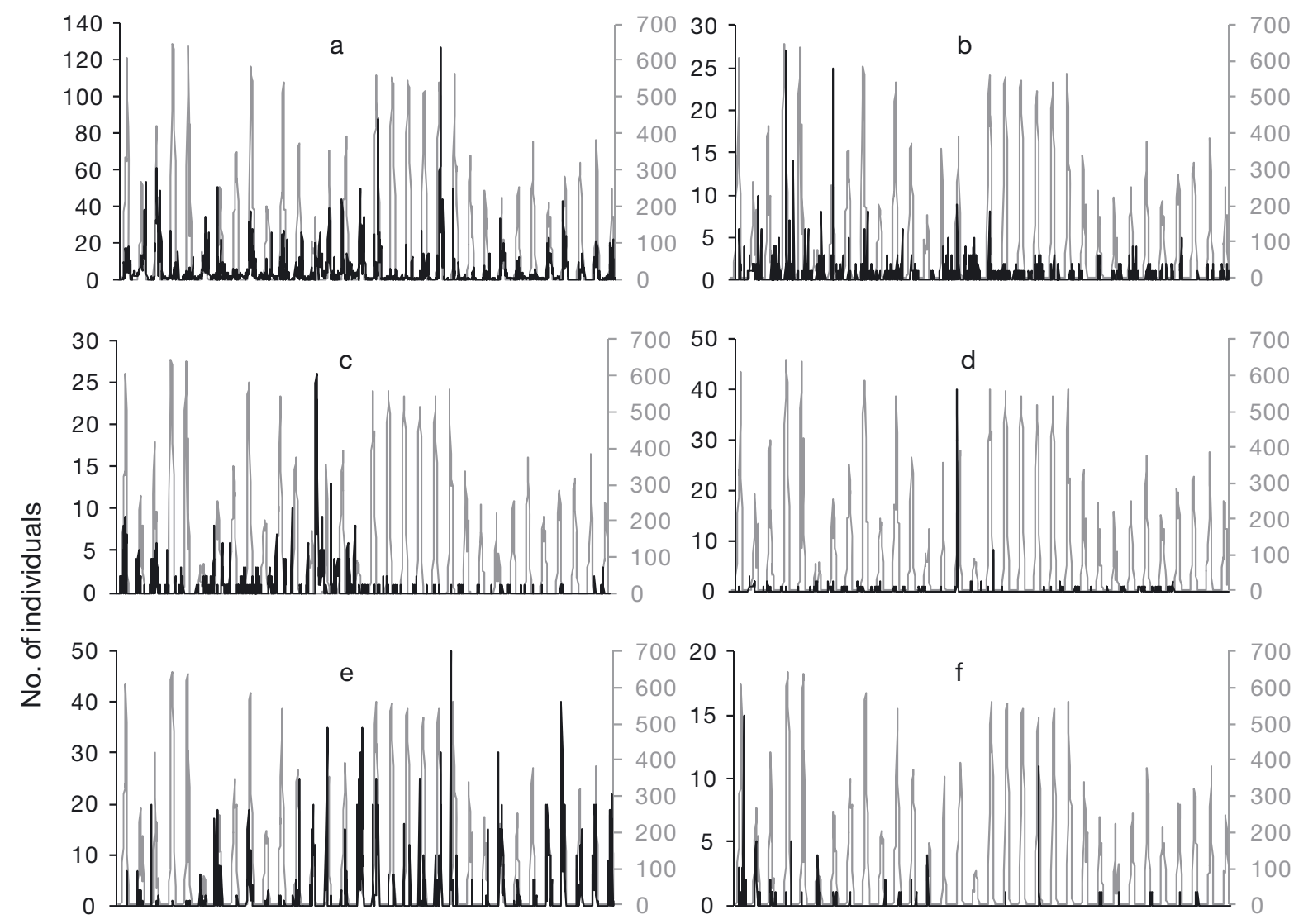

700

600

500

400

300

200

100
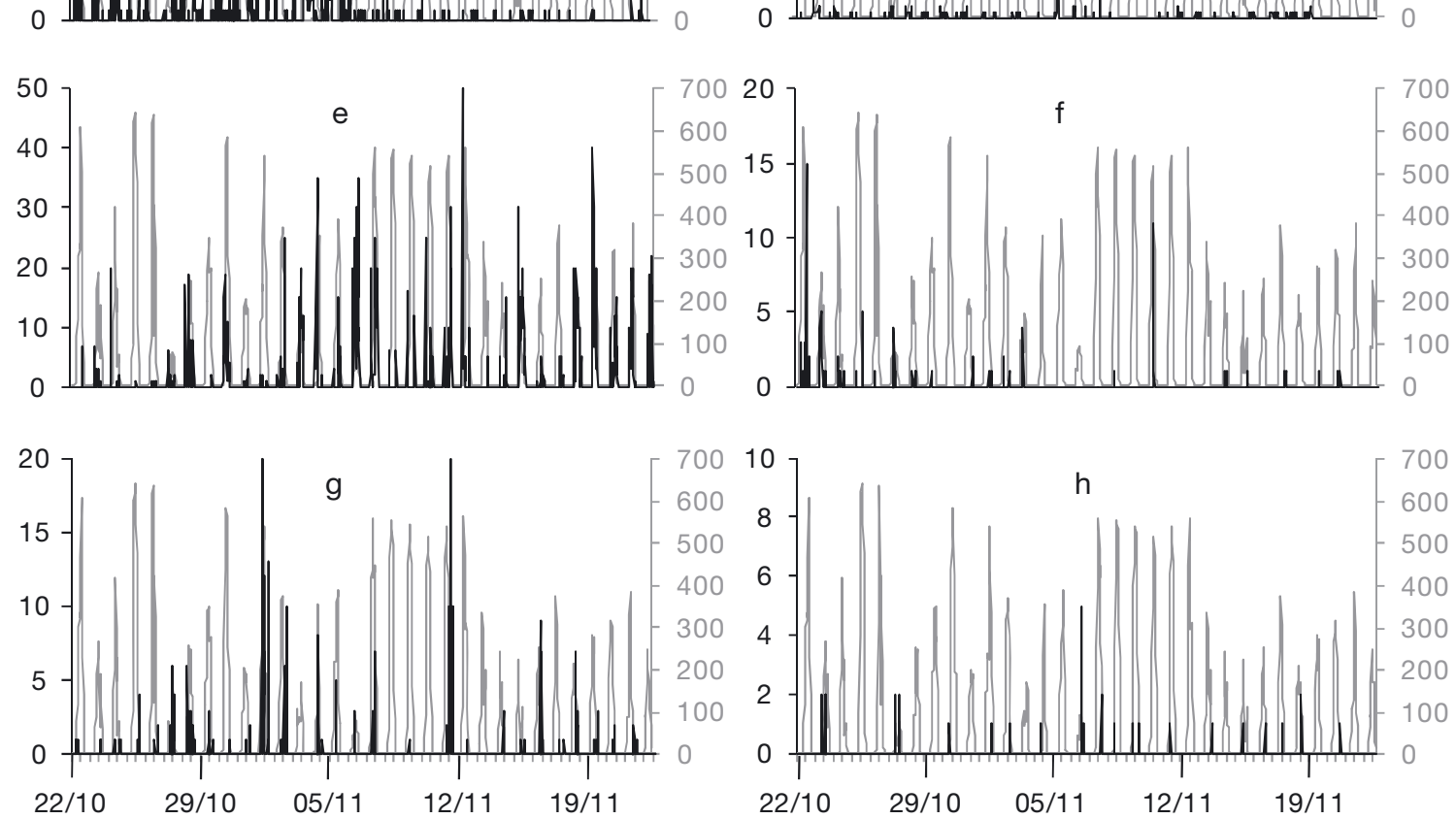

700
-600
-500
-400
-300
-200
-100
0

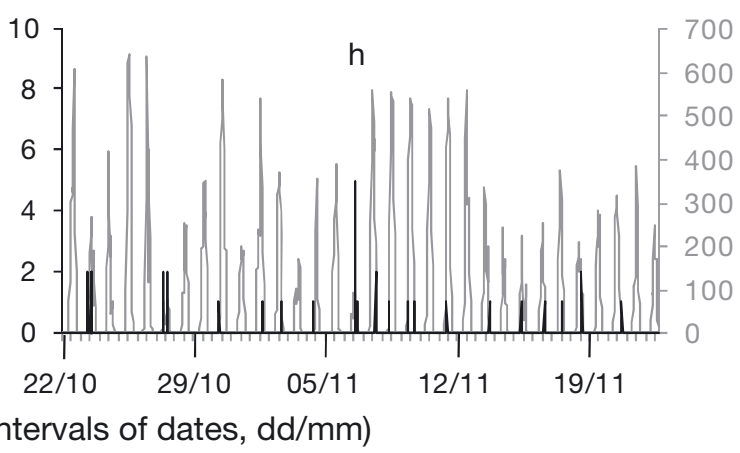

Fig. 2. (Above and on the next page.) Time series (black) of visual counts of fishes obtained during 1 mo of continuous observation in the Western Mediterranean coastal area where the OBSEA cabled video observatory is located. Fish counts and solar irradiance data (grey) are shown together as a measure of the coupling of species rhythms with daily fluctuations in environmental illumination. Note the differing abundances of fishes. (a) Fish assemblage; (b) fishes classified as unknown; (c) Apogon imberbis; (d) Atherina sp.; (e) Chromis chromis; (f) Coris julis; (g) Diplodus annularis; (h) Diplodus cervinus; (i) Diplodus sargus; (l) Diplodus vulgaris; (m) Dentex dentex; (n) Oblada melanura; (o) Serranus cabrilla; (p) Symphodus sp.; (q) Scorpaena sp.; (r) Spicara maena 

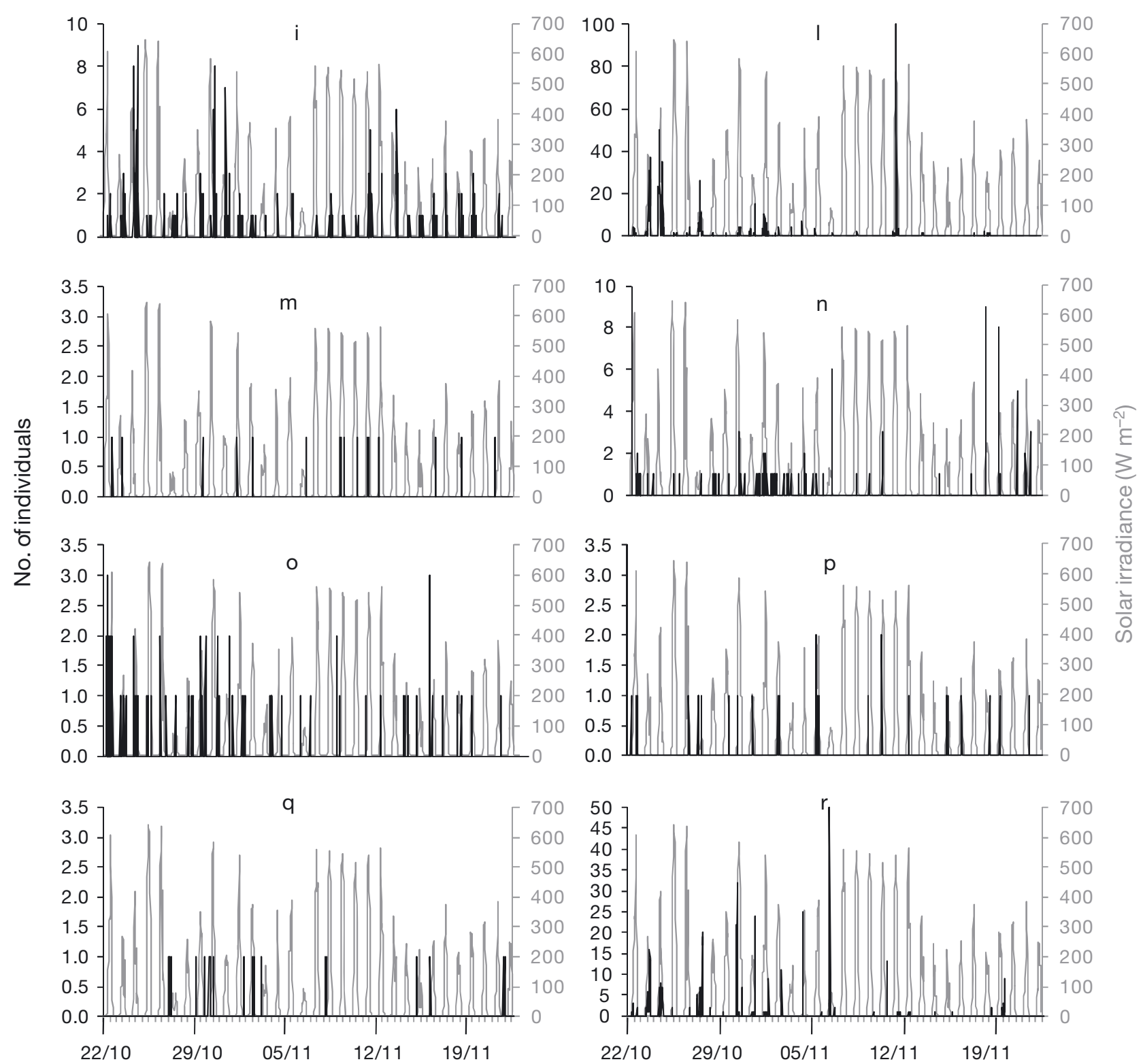

Video recording time (12 $\mathrm{h}$ intervals of dates, $\mathrm{dd} / \mathrm{mm}$ )

Fig. 2. (continued)

The waveform analysis detected another group of species with a significant crepuscular increase: Apogon imberbis, Oblada melanura, and Spicara maena (Fig. 3c,n,r, respectively). A third group, represented only by Atherina sp. (Fig. 3d), also showed a broad nocturnal increase, although a major peak occurred prior to sunrise. Of these 2 groups, only Atherina sp. was arrhythmic according to the periodogram analysis (Table 1). We also observed a nocturnal phase for Scorpaena sp. (Fig. 3q).

Additional findings resulted from the estimation of the duration of peaks in the visual counts, as deter- mined from the waveform onset and offset timing (i.e. the first and subsequent values above the MESOR; Table 1). Diurnal species showed an averaged peak span of smaller duration than that found for the nocturnal species $(9.9 \pm 1.0 \mathrm{~h}$ [mean $\pm \mathrm{SD}]$ and $13.5 \pm 1.4 \mathrm{~h}$, respectively). Species with crepuscular increases in detections showed smaller peak durations because they were in phase with the limited dusk and dawn periods. The durations of both crepuscular peaks for each species were summed and the results then averaged to yield an estimate of $6.5 \pm$ $2.2 \mathrm{~h}$. 


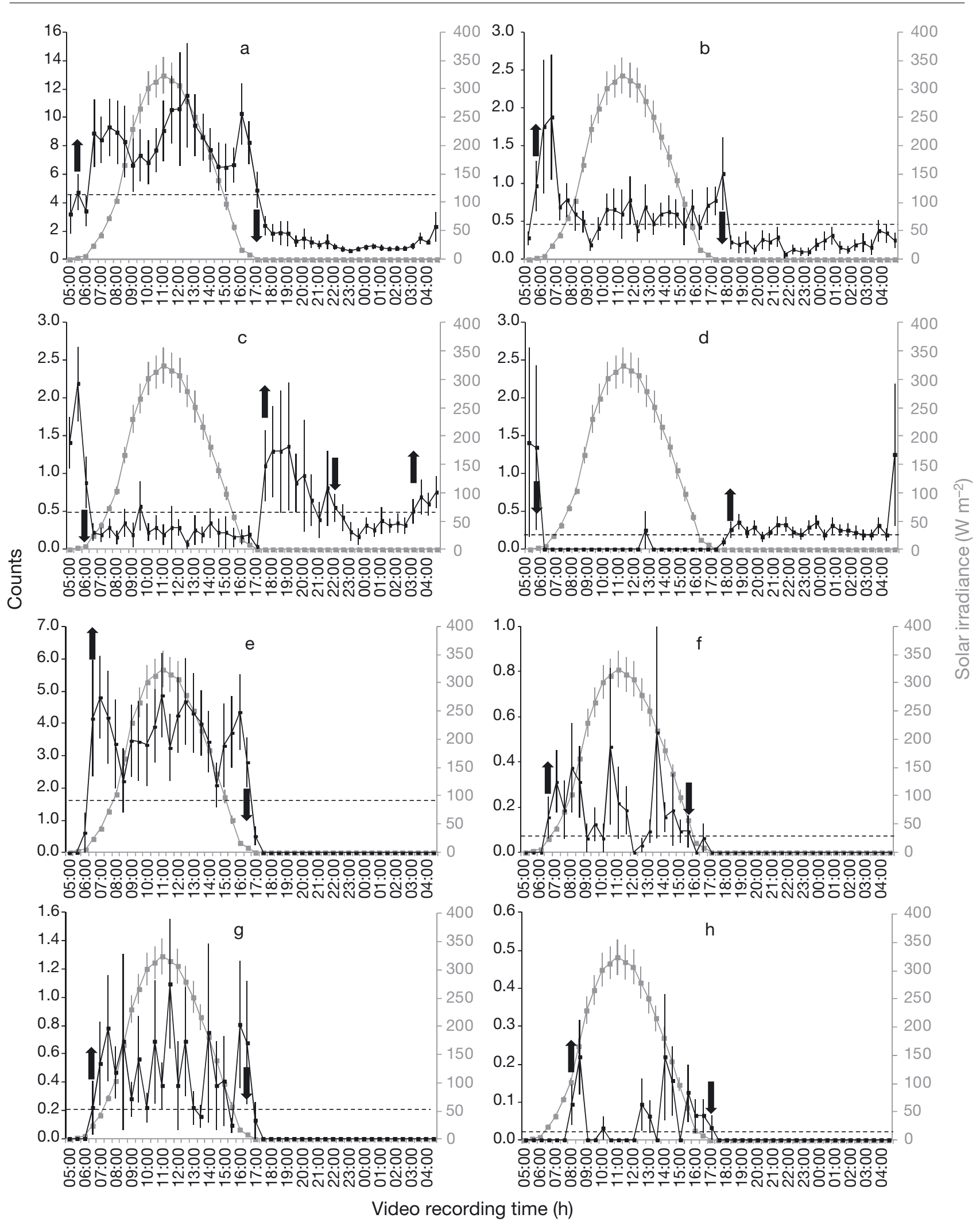

Fig. 3. (Above and on the next page.) Waveform analysis outputs (mean \pm SD) for time series of fish counts (black, note different scales) and irradiance data (grey) obtained from the Western Mediterranean coastal area during 1 mo of continuous video monitoring by the OBSEA cabled observatory. The phase of the rhythms of visual counts is identified by values above the MESOR (Midline Estimating Statistic of Rhythm value, dashed line), identifying the first and the later averaged counts above and below this reference line (i.e. activity onset and offset, respectively). The black arrows indicate these phases' temporal limits (reported in Table 1). (a-r) Species as in Fig. 2 

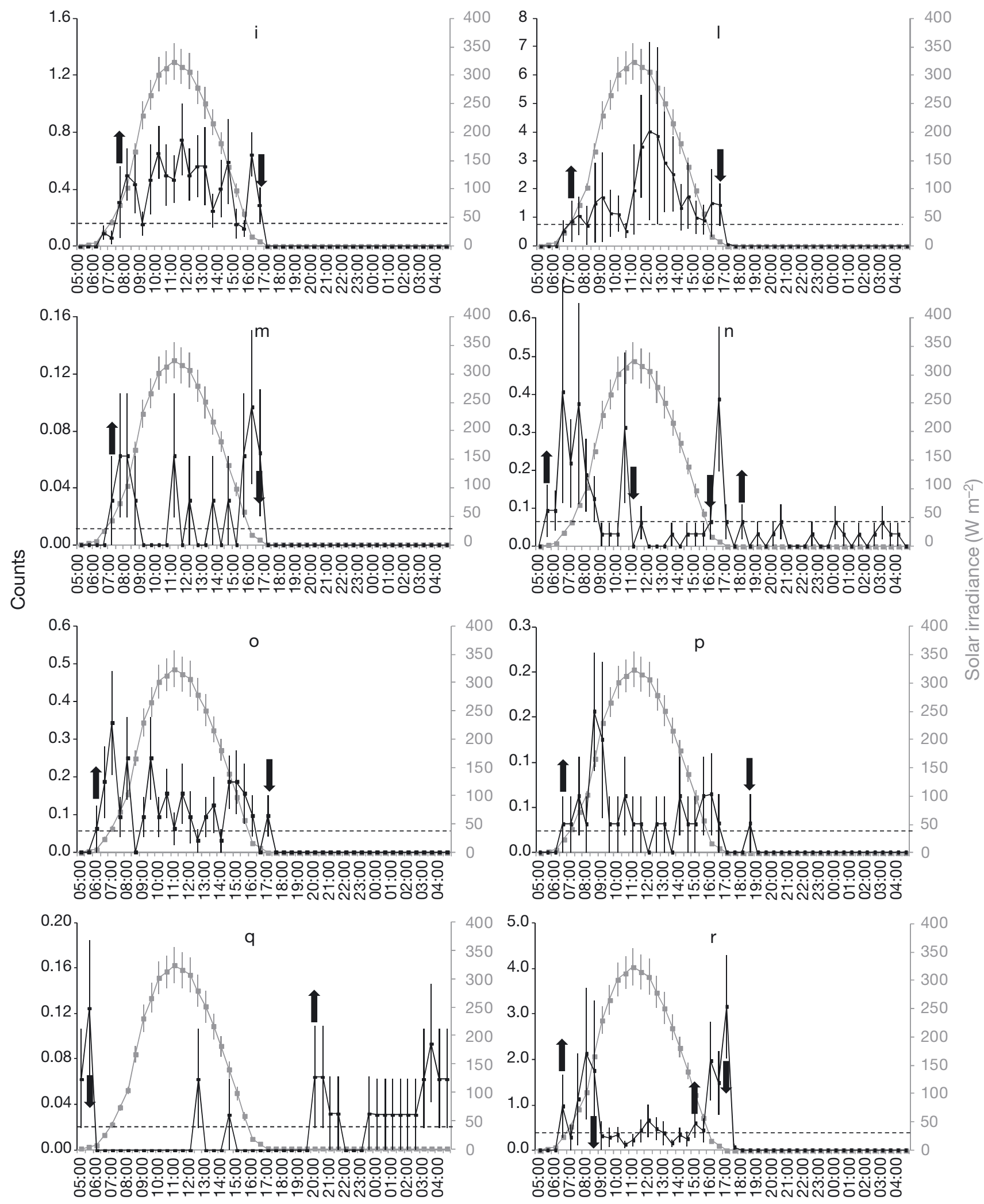

Video recording time (h)

Fig. 3. (continued) 


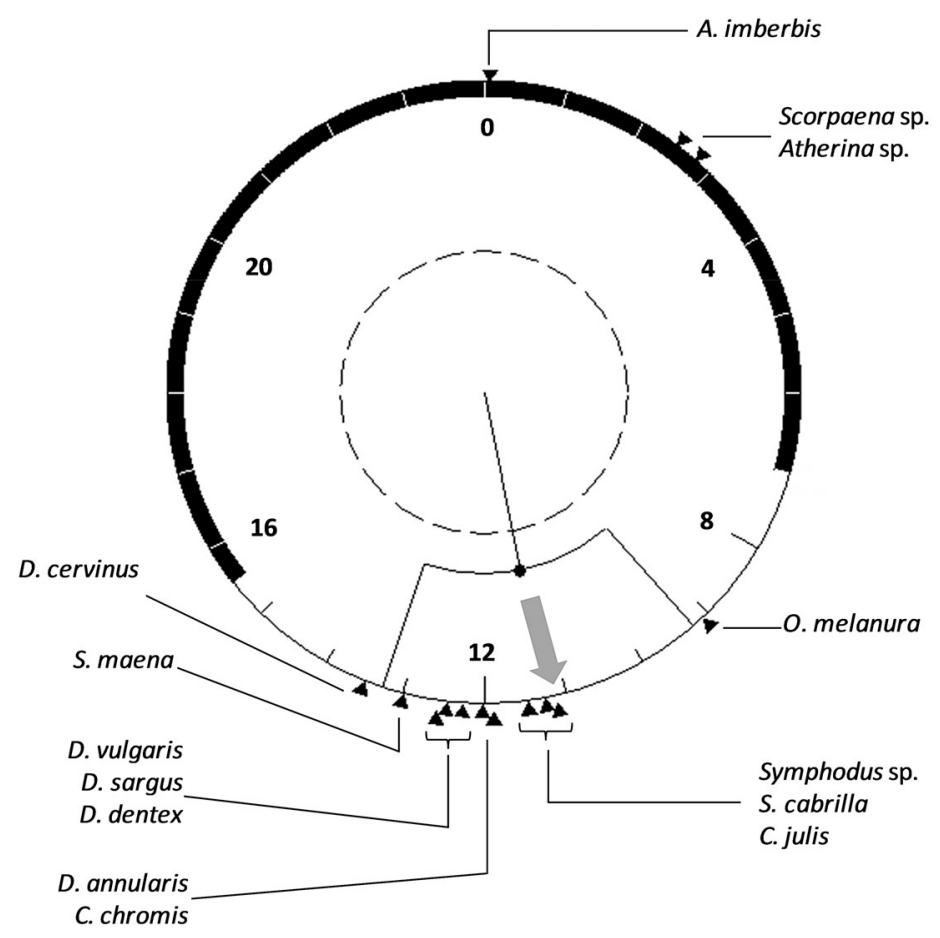

Fig. 4. Outputs from Rayleigh Z-test of the temporal clustering of visual counts. Time series phases for the different taxa (black triangles), as measured at the Western Mediterranean OBSEA coastal cabled observatory. Coordinates from 0 to 24 represent the $24 \mathrm{~h}$ cycle. The grey arrow is the phase of the irradiance data sets $(11: 18 \mathrm{~h})$. The dashed inner circumference defines the value for the significant threshold $(p<0.05)$ as required to measure the $\mathbf{r}$ vector strength (i.e. the thin black line reaching from the center to the trapezoid line and ending with a dot), whose orientation is given by the averaged temporal distributions of waveform phases. In particular, the trapezoid indicates the dispersion of the waveforms' temporal clustering. The thick black line is the averaged night duration, as defined by a waveform analysis of irradiance data (i.e. values below the MESOR, Midline Estimating Statistic Of Rhythm value). See Fig. 2 for full species names

The onset and offset of the waveform peaks for all species were compared with the average irradiance levels (also computed from waveform analysis). The peaks for all diurnal species started and ended between 06:00 and 08:00 $\mathrm{h}$ and 16:30 and 18:30 h, respectively. The onset and offset corresponded to irradiance values of 5.6 to 103.1 and 8.5 to $0.0 \mathrm{~W} \mathrm{~m}^{-2}$, respectively. Conversely, for the 2 taxa showing nocturnal visual count increases (Atherina sp. and Scorpaena sp.), the peak onset occurred between 18:00 and 20:00 $\mathrm{h}$ for irradiance values equal to $0 \mathrm{~W} \mathrm{~m}^{-2}$ (Table 1, Fig. 3d,q). Atherina sp. detections ceased before the sunrise under dark conditions (i.e. at 05:30 h), indicating the anticipation of sunrise. The Scorpaena sp. counts ended when the minimum illumination was equal to $2.8 \mathrm{~W} \mathrm{~m}^{-2}$ (at 05:30 h).
The Rayleigh $Z$-test showed a significant diurnal clustering $(p<0.05)$ of acrophases for the different taxa (Fig. 4). The acrophases of the majority of species clustered with a diurnal timing encompassing the acrophase of the irradiance data $(11: 18 \mathrm{~h})$. The acrophases of nocturnal species showed to be almost exactly antithetic to the one of the diurnal species, since chiefly occurring around midnight. Interestingly, only Oblada melanura showed a crepuscular phase (i.e. at sunrise) because the test selected the central part or the acrophase as the reciprocal distance between the 2 crepuscular peaks. Spicara maena showed a diurnal acrophase despite the major sunrise peak obtained by the waveform analysis for this species (Fig. 3r). The reason for this result was that the daytime visual counts were higher than the nighttime visual counts.

\section{DISCUSSION}

In this study, we used a cabled video observatory to quantify the fluctuations in counts of different fish species as a proxy for their swimming rhythms. The majority of species were found to be fully diurnal, with a few exceptions showing nocturnality or, unexpectedly, crepuscularity. Taken together, these results highlight the occurrence of marked changes in coastal fish communities as a response to daynight driven fluctuations in light intensity. The widespread use of such observational technology may furnish a foundation for the understanding of temporal functioning in marine ecosystems based on the precise characterization of behavioral responses of individuals within populations to cyclic habitat changes (Aguzzi et al. 2012).

\section{Methodological remarks for cabled observatory fish monitoring}

Several methodological remarks are provided here to evaluate the reliability of coastal cabled video observatory monitoring for the assessments and quantification of activity rhythms (Aguzzi et al. 2012). Such an evaluation should be conducted, considering that population and biodiversity assessments often sacrifice the high observation frequency needed at one site to study activity rhythms, for an increase in the amount of space included in the assessment (Aguzzi \& Company 2010).

Our results indicate that the time of sampling is relevant for species detection and that video monitoring 
should be conducted continuously over consecutive $24 \mathrm{~h}$ cycles. Furthermore, day-night monitoring should be repeated monthly because day-night fluctuations may occur in juxtaposition with larger population rhythms, such as those related to season. A comparison of our day-night species list with the seasonal list provided by Condal et al. (2012) for the same area reveals several differences. These authors conducted a similar seasonal video survey in which the fishes were always photographed during the day. Their list does not include nocturnal and crepuscular taxa such as Atherina sp. and Apogon imberbis. Moreover, other species occurring in the OBSEA area on a more seasonal basis (e.g. Boops boops, Mullus barbatus, Seriola dumerilii, Pagrus pagrus; see Condal et al. 2012 and references therein) were never detected by the $24 \mathrm{~h}$ scheduled video survey performed for the present study. This discrepancy may indicate a certain degree of seasonal population movement in and out of the cabled observatory area. It is possible that such movement would result from depth- or areaassociated processes of growth and reproduction (Harmelin-Vivien et al. 1995, Fabi \& Sala 2002).

The observed fluctuations in visual counts of fishes at OBSEA are undoubtedly indicative of some type of rhythm, but interpretations of count peaks in terms of significant increases in the swimming rate should be made cautiously within the context of species habitat use. For example, Atherina sp. was reported to be abundant during the night, but the count peak most likely does not indicate an increase in the overall swimming rate of individuals within the population. This species uses the water column and, most likely, moves closer to the bottom or to the artificial reef during the night to rest (Azzurro et al. 2007). More generally, studies in the Mediterranean based on different methods for tracking of individuals have indicated that detections decrease not only when animals rest on the seabed (i.e. as a sign of a true resting phase, e.g. in Serranids; March et al. 2010, Alós et al. 2011), but also when they move away from a certain location (Jadot et al. 2002, 2006). Activity can also change from diurnal to nocturnal if grouped distributions are replaced by isolated individuals, as is known to occur in different rocky or sandy zones (Begóut Anras et al. 1997). Within this framework, our results highlight the importance of information about habitat use by fishes prior to any inference about the possible nocturnal, diurnal, or crepuscular character of their swimming activity. This knowledge could be collected with networks of cabled video observatories, with a network geometry customized according to the home range of targeted species
(Horne \& Garton 2006). The synchronous comparison of fluctuations in video counts among different areas and depths may serve to clarify whether count peaks are due to activation or resting (e.g. sheltering) at one location.

Finally, the light-on conditions at filming may alter the behavior of coastal fishes (Widder at al. 2005, Harvey et al. 2012). For example, phototaxis is well known in nocturnal species, as shown by observations related to commercial fishing activity (BenYami 1976, Marchesan et al. 2005). Nocturnal species can easily detect weak light sources at a distance (Marchesan et al. 2009). Nevertheless, in the absence of acoustic cameras (whose impact on marine fauna remains to be determined; reviewed by Aguzzi et al. 2012), remote still or mobile video monitoring is presently one of the most efficient tools for performing non-invasive counts of marine fishes (e.g. Harvey et al. 2001, Ríha et al. 2008, Becker et al. 2010, Condal et al. 2012, Pelletier et al. 2012). In this context, we developed an automatic protocol for frame acquisition in synchrony with the on-and-off control of the lighting. Short-duration lighting (i.e. 2 s) at $30 \mathrm{~min}$ intervals most likely reduces the degree of photic contamination. In aphotic deep-sea areas, such contamination may alter the detection levels (Widder et al. 2005), but it does not appear to hinder the expression of activity rhythms in resident species even if it is constantly present (Aguzzi et al. 2010).

\section{Daily rhythms}

In the present study, we reported the occurrence of marked daily rhythms in visual counts in a group of temperate fishes for which a certain amount of information is already available (reviewed by Azzurro et al. 2007, 2013). The majority of species showed diurnal increases in detections (Fig. 4), and we found that the count peaks clustered at midday in different taxa around a similar irradiance level (Table 1, Fig. 4). Diurnal species such as those of the genus Diplodus show greater daytime abundances in artificial coastal areas (Santos et al. 2002, Azzurro et al. 2007). They are usually diurnal feeders (Bell \& Harmelin-Vivien 1983, Matić-Skoko et al. 2004). These species are generally low trophic-level predators that rely on vision to detect their prey. The same observation can be applied to Dentex dentex, which is a top visual predator (Antonucci et al. 2009). For species at a high trophic level, the higher levels of visual counts observed at the OBSEA were likely a product of an increase in swimming activity rate during the day. 
Incident solar light is highly variable in coastal areas (Horodysky et al. 2008, 2010) and has unpredictable effects on fish behavior (Hobson et al. 1981). In the present study, we obtained visual count patterns that were sufficiently strong to produce significant periodicities (Table 1) and temporally discernible waveform outputs (Fig. 3) for the majority of the species studied. This observation shows the importance for marine chronobiology of the video sampling technology used in this study. The rhythmic time series patterns obtained in the study demonstrate the capacity of the circadian systems of coastal fishes to determine the time of day despite light levels that can change markedly on a scale of hours (Fig. 2). Circadian input pathways (i.e. the visual organs) can smooth out high-frequency fluctuations in environmental illumination to obtain a reliable assessment of the time of day to be used as input for the entrainment of biological rhythms (Roenneberg \& Foster 1997). In the future, the video sampling technology used in this study could be applied to measure changes in daily behavioral patterns (from diurnal to nocturnal and vice versa) that may occur at different times of the year (Sánchez-Vázquez et al. 1998). Field data furnish important reference information for comparing swimming activity and its underlying coupling to light intensity via hormonal control (García-Allegue et al. 2001).

\section{Crepuscularity}

The use of this study's novel high-frequency video sampling technology enabled us to detect crepuscularity (i.e. the phasing of visual counts and, hence, of swimming rhythms with twilight conditions) for certain fish species. To the best of our knowledge, the occurrence of ultradian variations in the swimming behavior of coastal temperate fishes is still poorly documented in the field (reviewed by Willis et al. 2006). Ultradian variations are typically difficult to detect due to the extreme variability of fish distributions in the natural environment (Willis et al. 2006), and a high degree of temporal replication is surely needed to reveal the principal effects of twilight conditioning on individual behavior (Azzurro et al. 2013). Our sampling technology allows us to describe the occurrence of this phenomenon in fishes. Animals may be active at sunset and sunrise as a result of the entrainment of 2 coupled oscillators by twilight conditions (i.e. the dual-oscillator hypothesis; reviewed by Hastings 2001), as previously shown in a diverse range of marine phyla (Aguzzi \& Company 2010).
Acknowledgements. This research was funded by RITFIM (CTM2010-16274), ESONET (European Seas Observatory NETwork, Framework Program-FP7 Infrastructures-2005Global-4, ESONET 036851-2); European Multidisciplinary Seafloor Observation, Framework Program (EMSO-FP7 Infrastructures-2007-1, Proposal 211816), and Operatividad Laboratorio Submarino OBSEA (ACI2009-0983). Researchers from the Consejo Superior de Investigaciones Científicas (CSIC) and Universidad Politécnica de Cataluña (UPC) are members of the Associated Unit Tecnoterra. J.A. is a Postdoctoral Fellow of the Ramón y Cajal Program (Ministerio de Ciencia e Innovación; MICINN). The authors offer particular thanks to Dr. E. Azzurro (ISPRA, Italy) for his advice on species classification. The authors also thank the Servei Meteorologic de Catalunya (SMC) for providing irradiance data. The English revision was done by Mrs. V. Radovanovic.

\section{LITERATURE CITED}

Aguzzi J, Company JB (2010) Chronobiology of deep water continental margin decapods. Adv Mar Biol 58:155-225

Aguzzi J, Bullock NM, Tosini G (2006) Spontaneous internal desynchronization of locomotor activity and body temperature rhythms from plasma melatonin rhythm in rats exposed to constant dim light. J Circad Rhyt 4:6, doi: 10.1186/1740-3391-4-6

Aguzzi J, Costa C, Furushima Y, Chiesa JJ and others (2010) Behavioral rhythms of hydrocarbon seep fauna in relation to internal tides. Mar Ecol Prog Ser 418:47-56

Aguzzi J, Company JB, Costa C, Menesatti P and others (2011a) Activity rhythms in the deep-sea: a chronobiological approach. Front Biosci 16:131-150

Aguzzi J, Manuél A, Condal F, Guillén J and others (2011b) The new SEAfloor OBservatory (OBSEA) for remote and long-term coastal ecosystem monitoring. Sensors 11: 5850-5872

Aguzzi J, Company JB, Costa C, Matabos M and others (2012) Challenges to the assessment of benthic populations and biodiversity as a result of rhythmic behaviour: video solutions from cabled observatories. Oceanogr Mar Biol Annu Rev 50:233-284

Alós J, March D, Palmer M, Grau A, Morales-Nin B (2011) Spatial and temporal patterns in Serranus cabrilla habitat use in the NW Mediterranean revealed by acoustic telemetry. Mar Ecol Prog Ser 427:173-186

Antonucci F, Costa C, Aguzzi J, Cataudella S (2009) Ecomorphology of morpho-functional relationships in the family of Sparidae: a quantitative statistic approach. J Morphol 270:843-855

Azzurro E, Pais A, Consoli P, Andaloro F (2007) Evaluating day-night changes in shallow Mediterranean rocky reef fish assemblages by visual census. Mar Biol 151:2245-2253

Azzurro E, Aguzzi J, Maynou F, Chiesa JJ, Savini D (2013) Diel rhythms in shallow Mediterranean rocky-reef fishes: a novel chronobiological approach. J Mar Biol Assoc UK 93:461-470

Bahamon N, Sardà F, Aguzzi J (2009) Fuzzy diel pattern in commercial catchability of deep-water continental margin species. ICES J Mar Sci 66:2211-2218

Barans CA, Ardent MD, Moore T, Schmidt D (2005). Remote video revisited: a visual technique for conducting longterm monitoring of reef fishes on the continental shelf. Mar Tech Soc J 39: 80-88 
Batschelet E (1981) Circular statistics in biology. Academic Press, London

> Becker A, Cowley PD, Whitfield AK (2010) Use of remote underwater video to record littoral habitat use by fish within a temporarily closed South African estuary. J Exp Mar Biol Ecol 391:161-168

Bégout Anras ML, Lagardére JP, Lafaye JY (1997) Diel activity rhythm of seabass tracked in a natural environment: group effects on swimming patterns and amplitudes. Can J Fish Aquat Sci 54:162-168

Bell JD, Harmelin-Vivien ML (1983) Fish fauna of French Mediterranean Posidonia oceanica seagrass meadows. 2. Feeding habits. Tethys 11:1-14

Ben-Yami M (1976) Fishing with light. FAO of the United Nations, Fishing News Books, Oxford

- Cambras T, Vilaplana J, Campuzano A, Canal-Corretger MM, Carulla M, Díez-Noguera A (2000) Entrainment of the rat motor activity rhythm: effects of the light-dark cycle and physical exercise. Physiol Behav 70:227-232

> Chiesa JJ, Aguzzi J, García JA, Sardà F, de la Iglesia H (2010) Light intensity determines temporal niche switching of behavioral activity in deep water Nephrops norvegicus (Crustacea: Decapoda). J Biol Rhythms 25: $277-287$

Condal F, Aguzzi J, Sardà F, Nogueras M and others (2012) Seasonal rhythm in a Mediterranean coastal fish community as monitored by a cabled observatory. Mar Biol 159: 2809-2817

Dulčić J, Fencil M, Matić-Skoko S, Kraljević M, Glamuzina B (2004) Diel catch variations in a shallow-water fish assemblage at Duće Glava, eastern Adriatic (Croatian Coast). J Mar Biol Assoc UK 84:659-664

Dulčić J, Matić-Skoko S, Kraliević M, Fencil M, Glamuzina B (2005) Seasonality of a fish assemblage in shallow waters of Duće-Glava, eastern middle Adriatic. Cybium 29:57-63

Fabi G, Sala A (2002) An assessment of biomass and diel activity of fish at an artificial reef (Adriatic sea) using a stationary hydroacoustic technique. ICES J Mar Sci 59: 411-420

Fischer ST, Patzner RA, Müller CHG, Winkler HM (2007) Studies on the ichthyofauna of the coastal waters of Ibiza (Balearic Islands, Spain). Rostock Meeresbiol Beitr 18: 30-62

Froese R, Pauly D (2009) FishBase. www.fishbase.org. (accessed 21 Nov 2012)

García-Allegue R, Madri JA, Sánchez-Vázquez FJ (2001) Melatonin rhythms in European sea bass plasma and eye: influence of seasonal photoperiod and water temperature. J Pineal Res 31:68-75

Glover AG, Higgs ND, Bagley PM, Carlsson R and others (2010) A live video observatory reveals temporal processes at a shelf-depth whale-fall. Cah Biol Mar 51: 375-381

- Harmelin-Vivien ML, Francour P (1992) Trawling or visual censuses? Methodological bias in the assessment of fish populations in seagrass beds. Mar Ecol 13:41-51

Harmelin-Vivien ML, Harmelin-Vivien JG, Loboulleux V (1995) Microhabitat requirements for settlement of juvenile sparid fishes on Mediterranean rocky shores. Hydrobiologia 300-301:309-320

Harvey H, Fletcher D, Shortis M (2001) A comparison of the precision and accuracy of estimates of reef-fish lengths determined visually by divers with estimates produced by stereo-video system. Fish Bull 99:63-71
Harvey ES, Bulter JJ, McLean DL, Shand J (2012) Contrasting habitat use of diurnal and nocturnal fish assemblages in temperate Western Australia. J Exp Mar Biol Ecol 426427:78-86

> Hastings M (2001) Modeling the molecular calendar. J Biol Rhythms 16:117-123

Hobson ES, McFarland WN, Chess JR (1981) Crepuscular and nocturnal activities of Californian nearshore fishes, with consideration of their scotopic visual pigments and the photic environment. Fish Bull 79:1-30

Horne JS, Garton EO (2006) Selecting the best home range model: an information-theoretic approach. Ecology 87: 1146-1152

Horodysky AZ, Brill RW, Warrant EJ, Musick JA, Latour RJ (2008) Comparative visual function in five sciaenid fishes inhabiting Chesapeake Bay. J Exp Biol 211:3601-3612

Horodysky AZ, Brill RW, Warrant EJ, Musick JA, Latour RJ (2010) Comparative visual function in four piscivorous fishes inhabiting Chesapeake Bay. J Exp Biol 213: 1751-1761

Jadot C, Ovidio M, Voss J (2002) Diel activity of Sarpa salpa (Sparidae) by ultrasonic telemetry in a Posidonia oceanica meadow of Corsica (Mediterranean Sea). Aquat Living Resour 15:343-350

Jadot C, Donnay A, Acolas ML, Cornet Y, Bégout Anras ML (2006) Activity patterns, home-range size, and habitat utilization of Sarpa salpa (Teleostei: Sparidae) in the Mediterranean Sea. ICES J Mar Sci 63:128-139

Kronfeld-Schor N, Dayan T (2003) Partitioning of time as an ecological resource. Annu Rev Ecol Syst 34:153-181

Letourneur Y, Darnau AA, Salen-Picard C, Harmelin-Vivien M (2001) Spatial and temporal variations of fish assemblages in a shallow Mediterranean soft bottom area (Gulf of Fos, France). Oceanol Acta 24:273-285

> Longcore T, Rich C (2004) Ecological light pollution. Front Ecol Environ 2:191-198

López-Olmeda JF, Sánchez-Vázquez FJ (2010) Feeding rhythms in fish: from behavioral to molecular approach. In: Kulczykowska E, Popek W, Kapoor BG, (eds) Biological clock in fish. CRC Press, Boca Raton, FL, p 155-184

López-Olmeda JF, Noble C, Sánchez-Vázquez FJ (2012) Does feeding time affect fish welfare? Fish Physiol Biochem 38:143-152

March D, Palmer M, Alós J, Grau A, Cardona F (2010) Shortterm residence, home range size and diel patterns of the painted comber Serranus scriba in a temperate marine reserve. Mar Ecol Prog Ser 400:195-206

Marchesan M, Spoto M, Verginella L, Ferrero EA (2005) Behavioural effects of artificial light on fish species of commercial interest. Fish Res 73:171-185

Marchesan M, Spoto M, Ferrero EA (2009) Impact of artificial light on behavioural patterns of coastal fishes of conservation interest. Varstvo Narave 22:117-136

Maritorena S, Guillocheau N (1996) Optical properties of water and spectral light absorption by living and non-living particles and by yellow substances in coral reef waters of French Polynesia. Mar Ecol Prog Ser 131: 245-255

Matabos M, Aguzzi J, Robert K, Costa C, Menesatti P, Company JB, Juniper K (2011) Multi-parametric study of behavioural modulation in demersal decapods at the VENUS cabled observatory in Saanich Inlet, British Columbia, Canada. J Exp Mar Biol Ecol 401:89-96

Matić-Skoko S, Antolić B, Kraljević M (2004) Ontogenetic and seasonal feeding habits of the annular seabream 
(Diplodus annularis L.) in Zostera sp. beds, eastern Adriatic Sea. J App Ichthyol 20:376-381

Nelson W, Tong YL, Lee JK, Halberg F (1979) Methods for cosinor-rhythmometry. Chronobiologia 6:305-323

> Pelletier D, Leleu K, Mallet D, Mou-Tham G, Hervé G, Boureau M, Guilpart N (2012) Remote high-definition rotating video enables fast spatial survey of marine underwater macrofauna and habitats. PLoS ONE 7: e30536

> Petrakis G, MacLennan DD, Newton AW (2001) Day-night and depth effects on catch rates during trawl surveys in the North Sea. ICES J Mar Sci 58:50-60

Pulcini D, Costa C, Aguzzi J, Cataudella S (2008) Light and shape: a contribution to demonstrate morphological differences in diurnal and nocturnal teleosts. J Morphol 269:375-385

Reebs SG (2002) Plasticity of diel and circadian activity rhythms in fishes. Rev Fish Biol Fish 12:349-371

Refinetti R, Cornélissen G, Halberg F (2007) Procedures for numerical analysis of circadian rhythms. Biol Rhythm Res 38:275-325

Ríha M, Kubecka J, Mrkvicka T, Prchalová M and others (2008) Dependence of beach seine net efficiency on net length and diel period. Aquat Living Resour 21: 411-418

Roenneberg T, Foster RG (1997) Twilight times: light and the circadian system. Photochem Photobiol 66:549-561

Sánchez-Vázquez FJ, Azzaydi M, Martínez FJ, Zamora S, Madrid JA (1998) Annual rhythms of demand-feeding activity in sea bass: evidence of a seasonal phase inver-

Editorial responsibility: Ivan Nagelkerken, Adelaide, Australia sion of the diel feeding pattern. Chronobiol Int 15: $607-622$

Santos MN, Monteiro CC, Gaspar MB (2002) Diurnal variations in the fish assemblage at an artificial reef. ICES J Mar Sci 59:S32-S35

Sokolove PG, Bushell WN (1978) The chi square periodogram: its utility for analysis of circadian rhythms. J Theor Biol 72:131-160

Spyker KA, Van den Berghe EP (1995) Diurnal abundance patterns of Mediterranean fishes assessed on fixed transects by scuba divers. Trans Am Fish Soc 124:216-224

Tutman P, Glavić NA, Kožul V, Antolović N, Skaramuca D, Skaramuca BK (2007) Diel fluctuations of shallow water fish assemblage in Prapratna Bay (Southern Adriatic, Croatia). Rapp Comm Int Mer Médit 38:624

Tutman P, Glavić N, Kožul V, Antolović N, Skaramuca B (2010) Diel fluctuations in juvenile dominated fish assemblages associated with shallow seagrass and bare sand in southern Adriatic Sea, Croatia. Rapp Comm Int Mer Médit 39:688

Widder EA, Robison BH, Reisenbichler KR, Haddock SHD (2005) Using red light for in situ observations of deep-sea fishes. Deep-Sea Res I 52:2077-2085

Willis TJ, Millar RB, Babcock RC (2000) Detection of spatial variability in relative density of fishes: comparison of visual census, angling, and baited underwater video. Mar Ecol Prog Ser 198:249-260

> Willis TJ, Badalamenti F, Milazzo M (2006) Diel variability in counts of reef fishes and its implications for monitoring. J Exp Mar Biol Ecol 331:108-120

Submitted: December 5, 2012; Accepted: May 7, 2013 Proofs received from author(s): June 28, 2013 